\title{
Sex education
}

\author{
Susan Quilliam, BA, Cert Ed, MNLP, Freelance Writer, Broadcaster and Agony Aunt, Cambridge, UK
}

Correspondence: Ms Susan Quilliam.E-mail: susan@susanquilliam.com

Journal of Family Planning and Reproductive Health Care 2004; 30(2): 128-130

\section{Introduction}

At the time I learned about sex - nearly 50 years ago - the vast majority of sex education was done badly, judgementally or not at all. However, my mother, herself poorly taught 40 years previously, was determined to do things differently with me. So every question I asked she answered without embarrassment. Every confusion I had was cleared up. Through it all, the message was clear: sex is a wonderful and powerful thing - and because it's wonderful you need to do it with the right man, at the right time, in the right situation.

So it was with fascination that I received my latest Consumer Correspondent commission from the Journal, namely to explore how young women throughout Europe received their sex education. What would I find, a generation on from my own experiences, and two generations on from those of my mother?

My brief was not to do a research study, but simply to get a picture of women's experiences - and above all their opinions - on what they thought had worked, and what hadn't. To that end, 30 women aged between 20 and 30 years, from 18 European countries (see Author's Note), told me in detail how they'd learned about the birds and bees.

\section{Who?}

The first question I asked concerned whom the women had got their sex education from. No surprises there. A slight majority had learned from teachers, closely followed by mothers, then friends, then the media. Health professionals, I noted wryly, had almost no input - just two women out of the cohort reported that their main education came along that route.

\section{but I didn't really find out what it was all about until I made love.}

Just one woman, a Greek Cypriot, had been taught by her mother and father together - and painted a wonderfully moving picture: "My parents ... both sat me down one day and explained to me, with diagrams, about menstruation, erection and intercourse. I was ten and started my period a few weeks later - perfectly timed!" And, by the sound of it. perfectly played.

What was a surprise was the extent to which the written word played a part, particularly in Northern European countries. In particular, the explicit teen magazine, Bravo, figured in German and Dutch answers - while one Finnish woman reported that all her peer group was sent a magazine (with a cover-mounted condom) so that anyone who had missed sex education lessons didn't slip through the net!

Finally, a crucial point. Alongside these 'formal' teaching methods, most women reported receiving what they regarded as sex education directly - by experience. Time after time, comments on what had been learned were completed by the sentiment "... but I didn't really find out what it was all about until I made love". Note well: whatever's taught, in the kitchen, the classroom - or the clinic - will probably pale into insignificance when hormones start pumping!

\section{When?}

In terms of when sex education happened, there was a clear age progression from 'easy topics' to 'more challenging' ones. Gender differences were often learned before preschool - sometimes "so early that I can't remember". The reason for this early start: brothers. If a baby brother came along, 'willies and balls' were explained at the time. If not, women often didn't learn about men's physiology until puberty - or until they saw it in the flesh.

The mechanics of conception, pregnancy, menstruation, labour and childbirth were also dealt with opportunistically. If a woman had younger siblings, they acted as an audiovisual aid and she ended up knowing most things by mid-childhood. If she had older siblings, they acted as 'advance scouts', passing information down the line. Only children learnt in school. Most women, unlike earlier generations, were effectively prepared for menstruation before the event; only one woman had a horror story: "I was scared to death, I thought I would die. My father came in, saw the blood everywhere, blushed, gave me the pads and left."

\section{On my wedding night, I was a virgin and worried about how things would be.}

It was when it came to the 'act itself' that the learning age rose dramatically and difficulties kicked in. The vast majority of women didn't find out what sex truly involved until well into their teenage years; as mentioned before, a majority learned 'from experience' . The result - reports of confusion, uncertainty, nervousness. "On my wedrin" night, I was a virgin and worried about how things wr ulc be. I felt really stupid and I thought my husband would laugh at me." The other result, of course, is a worrying lack of preparation: "What sex itself involved [wasn't an issue] because I didn't plan on having sex until my wedding night. But then it became important when I was 15 , started to have sex - and didn't use a condom."

\section{What?}

Which leads us neatly on to another big gap that many women commented on, namely coverage of sexually transmitted infections (STIs). Although most women reported being taught about them - again in the mid- to late-teen years - the message sometimes didn't get through. It's chilling also to note that the age at which most women say they started to learn about STIs is way beyond the age where they could theoretically be having sex.

Above and beyond the facts, most women seemed to have been taught clear values in amongst their sex education. Sex is linked with love ... sex is special ... sex is something you do with someone you care for. But again, worryingly, many seemed to have learned these things late on - the average age was 14 years - and that didn' $t$ include the women who commented "I haven't learned that yet ... still wondering ... is there a relationship between sex and love?" Values need to be instilled from the start, not tagged on to sex education. 
Plus, even recently, a few women had been taught that sex was in some way wrong. And here - one of the few noticeable differences between countries - there was a clear division between Northern and Southern Europe. In general, the Germanic contingent - Denmark, Finland, Iceland, Germany, Holland - seemed to have been taught that sex was "natural ... a good thing". Conversely, the Southern Europe contingent - Spain, Italy, Portugal, Malta, Croatia - had been given the clear message that it was "wrong ... not very nice ... something to be afraid of" though the women who answered my survey had largely rebelled against this belief. (Greece, interestingly, bucked the Southern Europe trend; the Greek respondents overwhelmingly fell into the 'taught to be positive' camp.)

\section{$\ldots$ is there a relationship between sex and love?}

In fact, there was a clear undercurrent of women feeling that when it came to emotional literacy around sex, they both needed and wanted more support. They felt they had been taught the mechanics - but that was not all they wanted. They wanted to be able to handle sexual relationships. They wanted to be able to resist sexual pressure from partners and sexual competition with $\mathrm{p}$ ers They wanted to know how to wait for 'someone who cares', to wait for 'a stable and loving relationship' - and they wanted to know how to recognise that man and how to create that relationship.

\section{How?}

Did the women feel that their sex education was done well? Largely, the answer was yes. Time and time again, women said that the lessons they were taught, whether formal or informal, were good, valuable, successful. And, if I may make a personal comment, the success of those lessons was overwhelmingly reflected in the women themselves; they were thoughtful, responsible sexual decision makers. Something had obviously worked! (And, over the past half century, something has definitely changed.)

But despite that, women had major criticisms - and admitted personal vulnerabilities. School sex education was criticised as 'boring'. Families were condemned for not having an 'open approach'. Both general cultures and specific individuals were blamed for passing on negative values. "If [it hadn't have been] forbidden to talk about it, I would never have been so scared and tense - and still am!"

Most noticeable, however, was that sex education had been fraught with embarrassment. Two-thirds of the women reported some discomfort: mothers were shy when talking about sex ... tutors were flustered when delivering lessons. "I was a bit embarrassed, but not as embarrassed as the parents and teachers teaching me!"

\section{Why?}

These criticisms - of embarrassment, closed mindedness, negative attitudes to sex - are easily explainable where the women are from those European countries where religion or culture still judges as sex a taboo subject or one that needs to be controlled until marriage.

But what about the rest? The parents and teachers of other target women must have grown up through the 1960s where, in many European countries, sexual freedom was a reality. So why, when it came to teaching the next generation, did they not do a perfect job?

I have no provable answer. But let me instead hazard three guesses based on my current explorations - and on my many years of dealing with sexual queries. (1) The
"I was a bit embarrassed, but not as embarrassed as the parents and teachers teaching me!

parents and teachers themselves may have enjoyed sexual liberation in the $1960 \mathrm{~s}$ - but their own poor sex education left them with feelings of guilt that they passed on to their children. (2) The parents and teachers had simply forgotten how wonderful sex was, and so forgot to pass that message on to their children. (3) The parents and teac' ${ }^{1}$ r remembered all too well how wonderful sex was, inc didn't want to talk about it in public because they didn't want to allow children into their own private ecstasy.

\section{The next generation on}

I mention these issues in detail because to me they are at the core of this article. It's fascinating to examine the facts and figures of just how European women learn about sex. But if there are no conclusions on 'how to do better' then it's an exercise of little practical value. The bottom line is that we need to know why sex education goes wrong, and what can be done to improve it, in order to make it effective and positive for the next generation.

And so we need to look, with a clear eye, at why - and how - those who give sex education fall down. It isn't just a question of making sure that the right wall charts are used, the right sex pamphlets are given out. It isn't even just a case of talking through the issues face to face with young people. The one message that came across loud and clear from the European women I interviewed is that when sex education worked - delivering not only the facts but also the emotional resources to make the right choices - it worked because of how that education was delivered.

\section{My thoughts}

Here are my suggestions. First, I' d love both teachers and parents to become aware of the best practice in sexual education - and that might well include exploring and challenging their own attitudes to sex, because those will deeply influence the effectiveness of what they teach. Second, I' d love to see in-depth emotional literacy included as a regular part of all sex education. I know this is often achieved in schools, but with proper resourcing more could be done - and in classes small enough to avoid the horror of giggling mixed-gender groups. Third, it would be wonderful to see more projects such as British Parentline Plus's sex education pack, 'Time to Talk', where parents are supported to give the sex education their children want - informative, supportive and loving.

\section{The last word}

If any one theme came through from my interviewees it was that they valued - or wished that they had had - sex education from their parents. I asked, at one point, "How will you teach your daughters about sex?" and in response I received a flood of emotional answers - from eulogies about their own mothers' handling of the situation through to "God, I will try to make it better when I raise my children". The message was clear; overwhelmingly, these women would have liked to have received good sex education at home. And hence, overwhelmingly, these women want to be the first line of knowledge and support for their daughters.

\section{God, I will try to make it better when I} raise my children. 
They want to be the ones who tell their daughters about sex, who explain that it is a good and wonderful thing. They want to offer their daughters openness, the ability to ask any question and have it answered. They want to be - as one woman said - "my daughter's best friend" so that the subject is dealt with openly and without embarrassment. They want to be role models so that their daughters will not be subject to peer pressure, will not sleep with any man who asks, will become a clear and confident sexual woman.
That was certainly what my mother wanted for me. It is certainly what we must give to future generations.

\section{Author's Note}

A cohort of 30 women between the ages of 20-30 years from Britain, Belgium, Croatia, Cyprus, Denmark, Finland, France, Germany, Greece, Holland, Iceland, Ireland, Italy, Latvia, Malta, Poland, Portugal and Spain filled in a qualitative e-mail questionnaire during the period December 2003-January 2004.

\section{Editor's Note}

In the next issue of the Journal this column will cover the same European women's views on how they learned about contraception.

\title{
FROM OUR GP CORRESPONDENT: DR ROB'S BITS
}

\section{GP and clinical assistant in sexual health, Rob Hicks, reflects ...}

\author{
Rob Hicks, DRCOG, MRCGP, General Practitioner, Freelance Broadcaster and Writer, London, UK
}

Journal of Family Planning and Reproductive Health Care 2004; 30(2): 130

\section{Men want results on the web}

During my time in general practice, like most people I've seen how difficult men find it to come to see their doctor. This is particularly the case when all the doctors are female. A surgery that found itself in this situation now employs me to run a men's health clinic. Each week my clinic is full with men who have literally sat on their problems for a long time, who tell me that they "Didn't want to mention it to a lady doctor".

Anecdotally I've found that getting men to visit a genitourinary medicine (GUM) clinic is often harder. In general practice even though your average man may think that everyone in the waiting room believes him to be there because of a problem below his navel and above his knees, the problem may be, and often is, elsewhere. In a GUM clinic, however, the odds are very much against the problem being anywhere other than 'down there'.

It's well known that rates of chlamydia infection are on the increase and that often these infections are asymptomatic. A study published in The Lancet last year suggested that up to one in ten men may be infected with chlamydia when 800 army recruits in Scotland were tested as part of their routine medical examination. It also found that most of the men who tested positive had no symptoms.

A study in Sweden has tried to address these problems by offering 22-year-old men screening for chlamydia without needing to visit a clinic. Each of the 1000 men was sent a sample pot, questionnaire and information sheet, and asked to return the sample pot to the researchers for testing.

Using an individual code the men were able to access their results on the web. Although only 400 of the men approached to take part did so, the researchers commented that this was the highest recorded response for chlamydia testing in men of this age group. Three of the four men found to have the infection actually viewed their results on the web, the fourth needed to be contacted by researchers.

So well done to the Swedish researchers. But what next? Gonorrhoea rates of infection are also on the increase. Do they really think men are going to be so enthusiastic when they pull the 'little white loop' from the package and read about what they are supposed to do with it?

\section{University challenge}

The UK final of the 'SEXplained ... Foundation Student Challenge' takes place in April. More than 100 teams from

eight universities took part in the first round in February, answering a wide range of questions in a pub-style quiz. Most contestants were surprised at what they didn't know. As a result they will hopefully take more care and make sure they use condoms. As one of the people involved in checking the accuracy of questions and answers used, I was enormously relieved to find I could answer them correctly.

The winning team from the UK will be flown to Barbados in July for a week's holiday and a head-to-head challenge with the winning team from the 'SEXplained ... Foundation Student Challenge' in the West Indies.

The Foundation hopes that by engaging young people in different activities to raise their basic knowledge about sexual health, a more responsible attitude towards safer sex may begin to emerge.

Perhaps a quiz like this could be used as part of revalidation; it's far more interesting and entertaining than some of the required components. Let's face it - a week in Barbados is a very good incentive!

For more information visit http://www.SEXplained.com.

\section{Thought for the day}

It's become popular practice to have music playing within medical establishments. My first experience of this was classical music failing to silence the drill, or my anxiety, whilst I sat in the dentist's chair. Latterly, in general practice I have followed suit and I too now play classical music through my computer, something that my patients appear to approve of.

However, music can create difficulties, particularly if it's coming from a radio where you have no control over what is played. In my sexual health clinic the local radio playing in the examination room often makes things more uncomfortable than they should be. So be alert and if you hear any of the following, believe me it's probably better to switch the radio off.

Sex bomb

(Love lift us) Up where we belong

(I want a man with a) Slow hand

Do that to me one more time

Touch my bum
Tom Jones

Joe Cocker and Jennifer Warnes

Pointer Sisters

Captain and Tennille The Cheeky Girls 